\title{
Protective effect of histatin 1 against ultraviolet-induced damage to human corneal epithelial cells
}

\author{
GUO-QIANG HUANG ${ }^{1,2}$, GUO-GUO YI ${ }^{1}$, LAI-WEI WU ${ }^{1}$, SONG-FU FENG ${ }^{1}$, WEI WU ${ }^{1}$, \\ LING PENG $^{1}$, RUI-WEN YI ${ }^{1}$, WENBEI MA ${ }^{1}$ and XIAOHE LU ${ }^{1}$ \\ ${ }^{1}$ Department of Ophthalmology, Zhujiang Hospital, Southern Medical University, Guangzhou, Guangdong 510282; \\ ${ }^{2}$ Department of Ophthalmology, Meizhou People's Hospital, Meizhou, Guangdong 514031, P.R. China
}

Received December 8, 2015; Accepted June 22, 2017

DOI: $10.3892 / \mathrm{etm} .2017 .5503$

\begin{abstract}
The aim of the present study was to investigate the role of histatin 1 (Hst1) in human corneal epithelial cells (HCECs) exposed to ultraviolet (UV) radiation. Prior to UV irradiation for various durations, HCECs were pre-treated with different concentrations of Hstl and the effect on cell apoptosis and cell viability were examined by flow cytometry, alamarBlue ${ }^{\circledR}$ and MTT assays to determine the optimal concentration of Hst1 and UV dose. Cells were then subjected to quantitative PCR, ELISA and western blot analysis to determine the expression of cell damage-associated genes. HCECs exposed to UV light for $1 \mathrm{~h}$ displayed decreased viability when compared to that of control cells, and a $3 \mathrm{~h} \mathrm{UV} \mathrm{expo-}$ sure markedly increased the apoptotic rate of HECEs, while apoptosis was inhibited by pre-treatment with Hst1. UV radiation downregulated expression of insulin-like growth factor (IGF)-1 and B-cell lymphoma 2 (Bcl-2), while it upregulated $\mathrm{Bcl}-2$-associated $\mathrm{X}$ protein (Bax) expression. Hst1 protected HCECs against UV-induced damage by upregulating the expression of IGF-1 protein and increasing the Bcl-2/Bax ratio. In conclusion, Hst1 may prevent $\mathrm{UV}$-induced damage to corneal epithelial tissue injury and promote its healing.
\end{abstract}

\section{Introduction}

Ultraviolet (UV) radiation is generally divided into two spectral components consisting of UVB (290-320 nm) and UVA (320-400 nm). It is the main causative factor of skin cancer and also causes chronic damage to the eye, eventually leading to eye cancer (1). Cellular metabolic pathways generate molecules involved in causing photochemical damage to areas of skin exposed to UVB and UVA (2). For instance, UV

Correspondence to: Dr Xiaohe Lu, Department of Ophthalmology, Zhujiang Hospital, Southern Medical University, 253 Middle Gongye Avenue, Guangzhou, Guangdong 510282, P.R. China E-mail: luxh63@163.com

Key words: histatin1, human corneal epithelium, ultraviolet, wound healing radiation generates free radicals, including oxygen-derived radical species, which are known to cause lipid peroxidation in cellular membranes (3). In addition, it has been demonstrated that UV light directly damages DNA $(4,5)$, decreases mitochondrial function, induces apoptosis (4) and affects ocular structures, including the cornea, lens and retina (6).

Histatins (Hsts) are proteins found in saliva and are ubiquitously present in all living organisms. Hsts display anti-microbial and anti-fungal properties and are known to have a role in wound closure (7). Three major types of Hsts (Hst1, 3 and 5) have been identified, and Hst1 is encoded by the gene HTN1 (8). In humans, Hsts are secreted into saliva by the parotid and submandibular glands (9). Oudhoff et al (10) reported that Hst1 not only promotes cell-substrate adhesion but also cell-cell adhesion, which facilitates the creation of epithelial barrier junctions. Hsts are ubiquitously present in all living organisms, and in addition to their anti-microbial functions, also appear to have growth-stimulating properties (10). While Hsts exert wound-healing effects in cultured epithelial cells, it has not been determined whether they protect human corneal epithelial cells (HCECs) from damage induced by exposure to UV radiation. Insulin-like growth factor (IGF)-1 expressed in corneal tissues is known to promote corneal epithelial cell proliferation, migration and differentiation, and to have an important role in maintaining normal corneal growth. Individuals with diabetic retinopathy display an increased expression of IGF-1 (11), which enhances the ability of their corneal epithelial cells to heal after being damaged.

The present study investigated the role of Hst1 in HCECs damaged by exposure to UV radiation. The results suggested that Hst1 may be a potential therapeutic agent for protecting HCECs against damage induced by UV radiation.

\section{Materials and methods}

Cell culture and treatment. HCECs from cultures of $<30$ passages were provided by the Department of Plastic, Shandong Provincial Qianfoshan Hospital affiliated Shandong University (Shandong, China); the cells were purchased from the American Type Culture Collection (Manassas, VA, USA). The HCECs were cultured in a growth medium consisting of $10 \%$ fetal bovine serum (Invitrogen; Thermo Fisher Scientific, Inc., Waltham, MA, USA), $100 \mathrm{IU} / \mathrm{ml}$ penicillin (Sigma-Aldrich; 
Merck KGaA, Darmstadt, Germany), 100 IU/ml streptomycin (Sigma-Aldrich; Merck KGaA) and Dulbecco's modified Eagle's medium/F12 (Invitrogen; Thermo Fisher Scientific, Inc.). The cells were maintained in a humidified atmosphere with $5 \% \mathrm{CO}_{2}$ at $37^{\circ} \mathrm{C}$. When the cells had formed a sheath on the bottom of the culture vessel, they were re-suspended by incubation with $0.125 \%$ trypsin, collected and seeded at a ratio of $1: 2$ in a fresh $25 \mathrm{~cm}^{2}$ culture flask. They were then sub-cultured in $5 \mathrm{ml}$ complete medium.

Exposure of cells to UV light. When the HCECs had grown to $\sim 80 \%$ confluency, the residual growth medium was discarded and replaced with $1 \mathrm{ml}$ pre-heated PBS. The cells were then gently agitated and washed with PBS. Next, the culture dish lids were removed and the cells were placed $12 \mathrm{~cm}$ below an UVB lamp (wavelength range, 250-350 nm; peak wavelength, $297 \mathrm{~nm}$ ) for direct irradiation. The intensity of UV radiation directly measured at a $12-\mathrm{cm}$ vertical distance below the UVB lamp was $20 \mu \mathrm{w} / \mathrm{cm}^{2}$, and was calculated using the following formula: $\mathrm{H}=\mathrm{TxE}$; where $\mathrm{H}$ was the radiant exposure $\left(\mathrm{J} / \mathrm{cm}^{2}\right)$, $\mathrm{t}$ was the exposure duration (seconds) and $\mathrm{E}$ was the measured irradiance $\left(\mathrm{W} / \mathrm{cm}^{2}\right)$. Radiation dosages corresponding to UVB irradiation times of 1,2 and $3 \mathrm{~h}$ were $0.072,0.144$ and $0.216 \mathrm{~J} / \mathrm{cm}^{2}$, respectively. Following irradiation, the cells were once again cultured in fresh medium.

Hst1 treatment. Hst1 was obtained from the Chinese Peptide Company (Hangzhou, China). The sequence was DSHEKR HHGYRRKFHEKHHSHREFPFYGDYGSNYLYDN. Four doses of Hst1 $(0,10,50$ and $100 \mu \mathrm{g} / \mathrm{ml})$ were added to the cells for $12 \mathrm{~h}$ prior to UV radiation treatment or other assays.

AlamarBlue $e^{\circledR}$ assay. The viability of HCECs was measured by examining their general health and proliferation using the alamarBlue ${ }^{\circledR}$ assay. HCECs $\left(\sim 10^{5}\right)$ were seeded into the wells of 24 -well plates and then incubated at $37^{\circ} \mathrm{C}$ with $5 \% \mathrm{CO}_{2}$ for $24 \mathrm{~h}$. The cells were exposed to UV light when the cultures were $\sim 75 \%$ confluent. Following UV exposure, the cultures were again incubated for $24 \mathrm{~h}$. Subsequently, the medium was aspirated from each well and the cells were rinsed with $1 \mathrm{ml}$ culture medium containing serum. After aspirating the residual medium, $1 \mathrm{ml} \mathrm{10 \%}$ alamarBlue ${ }^{\circledR}$ (Thermo Fisher Scientific, Inc.) plus growth medium without serum was added to each well, and the cells were incubated at $37^{\circ} \mathrm{C}$ for $3 \mathrm{~h}$. Following incubation, the fluorescence in each well was measured at $530 / 590 \mathrm{~nm}$ using a Thermo Plate microplate reader (Rayto Life and Analytical Science Co. Ltd., Shenzhen, China).

Proliferation of cultured cells. The proliferation of cultured HCECs was evaluated using the MTT colorimetric assay, which is based on the chemical reduction of MTT by living cells to form formazan crystals. In brief, HCECs were seeded into 96 -well tissue culture plates $\left(2 \times 10^{4}\right.$ cells/well) and incubated at $37^{\circ} \mathrm{C}$ under $5 \% \mathrm{CO}_{2}$ for $0,12,24$ or $48 \mathrm{~h}$. Next, the cells were incubated in $100 \mu \mathrm{l}$ MTT solution $(5 \mathrm{mg} / \mathrm{ml}$; cat. no. M6494; Invitrogen; Thermo Fisher Scientific, Inc.) for $3 \mathrm{~h}$, and then washed with PBS. The purple formazan crystals formed in living cells were then solubilized with dimethylsulfoxide (Invitrogen; Thermo Fisher Scientific, Inc.). The absorbance of the formazan solution was measured at $450 \mathrm{~nm}$ using a Thermo Plate microplate reader (Rayto Life and Analytical Science Co. Ltd.).

Cell apoptosis analysis. Apoptosis assays were performed using the Annexin-V-FITC Apoptosis Detection Kit (Nanjing KeyGen Biotech Co., Ltd., Nanjing, China) according to the manufacturer's instructions. Early apoptotic cells were defined as annexin-V-positive or propidium iodide-negative cells. Analyses were performed using a Beckman Gallios Flow Cytometer (Beckman Coulter, Brea, CA, USA).

Semi-quantitative polymerase chain reaction ( $q P C R)$. Total cellular RNA was isolated using TRIzol reagent (Takara Biotechnology Co., Ltd., Dalian, China). The first strand cDNA was synthesized using the PrimeScript ${ }^{\mathrm{TM}}$ 1st strand cDNA Synthesis kit (cat. no. 6110A; Takara Biotechnology Co., Ltd.). Next, RNA samples were subjected to qPCR analysis to measure their levels of IGF-1, B-cell lymphoma 2 (Bcl-2) and $\mathrm{Bcl}-2$-associated $\mathrm{X}$ (Bax) mRNA. The primers used for IGF-1, Bcl-2, Bax and GAPDH are listed in Table I. qPCR reactions were conducted using the $\mathrm{SYBR}^{\circledR}$ Fast qPCR mix (cat. no. RR430A; Takara Biotechnology Co., Ltd.). The PCR amplification conditions were as followings, pre-denaturation at $95^{\circ} \mathrm{C}$ for $30 \mathrm{sec}$, denaturation at $95^{\circ} \mathrm{C}$ for $5 \mathrm{sec}$ and annealing at $60^{\circ} \mathrm{C}$ for $10 \mathrm{sec}(40$ cycles). The PCR products in $4 \mu \mathrm{l}$ of the product mixture were separated by electrophoresis on a $1.25 \%$ agarose gel, the gel was stained with ethidium bromide solution for $15 \mathrm{~min}$ at $<50^{\circ} \mathrm{C}$. The densities of the various complementary DNA bands were analyzed by scanning their absorbance areas with an AlphaImager gel imaging and analysis system (ProteinSimple, San Jose, CA, USA). Alphalmager ${ }^{\circledR}$ Ger Documentation (version 1.0; ProteinSimple) was used to assess the density the bands. Band intensity values for IGF-1, Bcl-2 and Bax were normalized to those of GAPDH and the relative expression was calculated using the $2^{-\Delta \Delta \mathrm{Cq}}$ method (12).

ELISA. Cellular levels of malondialdehyde (MDA; cat. no. A003-4) and superoxide dismutase (SOD; cat. no. A001-1) were detected using ELISA kits (both Nanjing Jiancheng Bioengineering Institute, Nanjing, China) according to the manufacturer's instructions. In brief, $100 \mu 1$ of a prepared standard solution or sample was added to each well of a sample plate and incubated overnight at $4^{\circ} \mathrm{C}$. The plate was then washed four times with buffer, and subsequently, $100 \mu \mathrm{l}$ biotinylated primary antibody was added to each well, followed by incubation at room temperature (RT) for $1 \mathrm{~h}$. The plates were then washed four times with buffer and incubated with peroxidase-conjugated secondary antibody for $45 \mathrm{~min}$. Next, the plates were washed three times with buffer, and $100 \mu 1$ tetramethylbenzidine was added to each well to induce a color reaction at $\mathrm{RT}$, which was stopped after $30 \mathrm{~min}$. The optical density of each well at $450 \mathrm{~nm}$ was determined using an automated microplate reader.

Western blot analysis. Cells were harvested in radioimmunoprecipitation assay lysis buffer and centrifuged at $13,200 \mathrm{x} g$ for $15 \mathrm{~min}$ at $4^{\circ} \mathrm{C}$. The supernatant fractions were collected and the protein concentration was determined by the Bio-Rad Protein Assay kit II (cat. no. 5000002; Bio-Rad Laboratories, Inc., Hercules, CA, USA). Protein samples (40 $\mu \mathrm{g} / \mathrm{lane}$ 
Table I. Primer pairs used for polymerase chain reaction.

Primers (5'-3')

\begin{tabular}{lll}
\cline { 2 - 3 } Gene & \multicolumn{1}{c}{ Forward } & \multicolumn{1}{c}{ Reverse } \\
\hline GAPDH & GGCCTCCAAGGAGTAAGAAA & GCCCCTCCTGTTATTATGG \\
IGF-1 & TAAGGAGGCTGGAGATGTATTGC & GGCTGATACTTCTGGGTCTTGG \\
Bcl-2 & GGGAGGATTGTGGCCTTCTTT & TGTGCAGGTGCCGGTTCAG \\
Bax & TTTGCTTCAGGGTTTCATCCA & TGAGACACTCGCTCAGCTTCTTG
\end{tabular}

IGF, insulin-like growth factor; Bcl-2, B-cell lymphoma 2; Bax, Bcl-2-associated X protein.

of total protein) were separated by $12 \%$ SDS-PAGE and electro-transferred to polyvinylidene difluoride membranes (cat. no. IPVH00010; EMD Millipore, Billerica, MA, USA). The membranes were then incubated with 5\% non-fat skimmed milk in Tris-buffered saline containing $0.1 \%$ Tween 20 (TBST) for $1 \mathrm{~h}$. Next, the membranes were incubated overnight with anti-IGF-1 (1:1,000; cat. no. ab9572; Abcam, Cambridge, UK), anti-Bcl-2 (1:1,000; cat. no. 2872), anti-Bax (1:1,000; cat. no. 5023) and anti-GAPDH (1:2,000; cat. no. 97166) (all Cell Signaling Technology, Inc., Danvers, MA, USA) primary antibodies at $4^{\circ} \mathrm{C}$, followed by a subsequent incubation with horseradish peroxidase-conjugated goat anti-mouse (cat. no. A4416) and anti-rabbit (cat. no. A6154) secondary antibodies (both 1:10,000; Sigma-Aldrich; Merck KGaA) for $1 \mathrm{~h}$ at room temperature. The membranes were then rinsed with TBST, blots were visualized with enhanced chemiluminescence western blot detection reagents (cat. no. 321096; Thermo Fisher Scientific, Inc.) and then exposed to an X-ray film (Kodak, Rochester, NY, USA). The resultant protein bands were scanned using a Gel-doc2000 imaging system (Bio-Rad Laboratories, Inc.) and analyzed using Quantity One 1-D Analysis software (version 4.6.9; Bio-Rad Laboratories, Inc.).

Statistical analysis. All data were analyzed using Predictive Analytics Software for Windows (version 18.0; IBM Corp., Armonk, NY, USA). Statistical significance was assessed by Student's t-test and one-way analysis of variance followed by Tukey's post-hoc test. Statistical values are expressed as the mean \pm standard error of the mean. $\mathrm{P}<0.05$ was considered to indicate a statistically significant difference between groups. All experiments were performed at least three times.

\section{Results}

Cell model of UV irradiation-induced injury. The percentage of HCECs undergoing apoptosis increased with increasing exposure to UV light (Fig. 1A). While 29.1\% of cells exposed to UV radiation for $2 \mathrm{~h}$ had entered apoptosis (early and late apoptosis), this percentage increased to $48.4 \%$ after $3 \mathrm{~h}$ of exposure, indicating that UV radiation can greatly damage HCECs (Fig. 1B). Furthermore, cells exposed to UV radiation for $3 \mathrm{~h}$ demonstrated a significant loss of viability as measured by alamarBlue ${ }^{\circledR}$ assay, while a $1 \mathrm{~h}$ exposure had little or no effect (Fig. 1C). Simultaneously, a UV-free group was set as a control, and cells in this group were treated under the above conditions apart from being irradiated with UV light. Cell apoptosis slightly increased in the UV-free group with time; however, compared with this group at $0 \mathrm{~h}$, no significant differences were demonstrated. Based on these results, a 2 h UV radiation exposure period (total radiation dosage, $0.144 \mathrm{~J} / \mathrm{cm}^{2}$ ) was selected for use in the subsequent UV-induced cell damage model.

Hst1 enhances the proliferation and reduces oxidative stress in HCECs. Three concentrations of Hst1 (10, 50 and $100 \mu \mathrm{g} / \mathrm{ml}$ ) were used to treat the HCECs prior to UV radiation. Cell proliferation, which was assessed by the MTT assay was increased in the 10,50 and $100 \mu \mathrm{g} / \mathrm{ml}$ Hst1 treatment groups. Cell proliferation was significantly induced in the $50 \mu \mathrm{g} / \mathrm{ml} \mathrm{Hst} 1$ treatment group compared with the control group (Fig. 2A). However, cell proliferation in the $100 \mu \mathrm{g} / \mathrm{ml} \mathrm{Hst1} \mathrm{treatment} \mathrm{group} \mathrm{was} \mathrm{markedly} \mathrm{lower}$ compared with the $10 \mu \mathrm{g} / \mathrm{ml}$ Hst 1 treatment group, but it remained higher than that in the control group. Furthermore, by performing an MTT assay the proliferation of irradiated HCECs pre-treated with Hst1 was demonstrated to be increased compared with that of untreated irradiated cells. The same cells were also subjected to analysis of cellular SOD and MDA levels. The results revealed that the Hst1 treatment groups had lower SOD levels (Fig. 2B), but higher MDA levels (Fig. 2C) than the control group $(0 \mu \mathrm{g} / \mathrm{ml}$ and UV irradiated). When pre-treated with $50 \mu \mathrm{g} / \mathrm{ml} \mathrm{Hst1,} \mathrm{the} \mathrm{intra-}$ cellular content of SOD was significantly decreased, while the MDA concentration was increased when compared with that in the control group. Therefore, $50 \mu \mathrm{g} / \mathrm{ml}$ was selected as the concentration of Hstl to be used in the subsequent experiments.

Hstl protects HCECs against UV-induced damage. It was then examined how Hst1 protected HCECs against UV-induced damage. qPCR analysis demonstrated that the mRNA expression levels of IGF-1 (Fig. 3A) and Bcl-2 (Fig. 3B) were upregulated after pre-treatment of HCECs with $50 \mu \mathrm{g} / \mathrm{ml} \mathrm{Hst1}$ prior to irradiation, while and Bax was downregulated (Fig. 3C). Furthermore, Hst1 inhibited irradiation-induced apoptosis in HCECs (Fig. 4A and B). In addition, Hst1 was found to affect IGF-1, Bcl-2 and Bax protein expression in a similar way to the corresponding mRNA levels: The expression of IGF-1 and Bcl-2 in HCECs treated with Hst1 was significantly upregulated when 

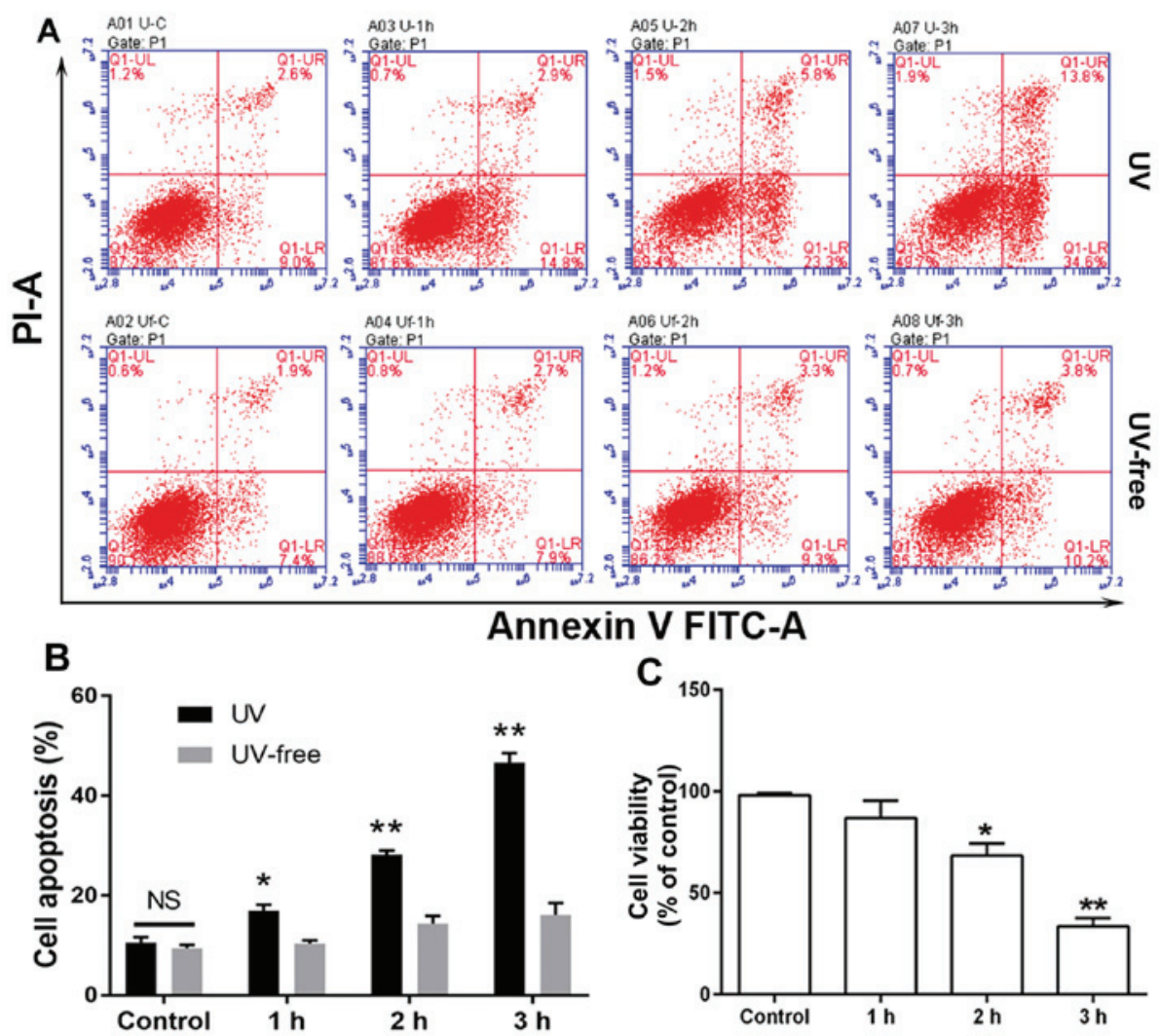

Figure 1. Apoptotic status and viability of HCECs irradiated with UV light for 1,2 and $3 \mathrm{~h}$ as well as cells not subjected to irradiation. (A) Flow cytometric dot plots of Annexin V-FITC and PI-stained HCECs irradiated with UV light; (B) Percentage of HCECs undergoing apoptosis; (C) Viability of HCECs (\% of control) was assessed using the alamarBlue ${ }^{\circledR}$ assay. Values are expressed as the mean value of three independent experiments \pm the standard deviation. ${ }^{*} \mathrm{P}<0.05$; ${ }^{* *} \mathrm{P}<0.01$ vs. control group. FITC, fluorescein isothiocyanate; PI, propidium iodide; UL, upper left; LR, lower right; UV, ultraviolet; HCEC, human corneal epithelial cell; NS, no significance; Uf, UV-free.

A

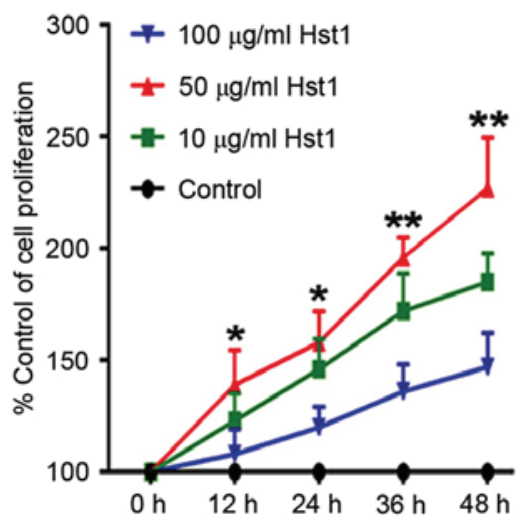

B

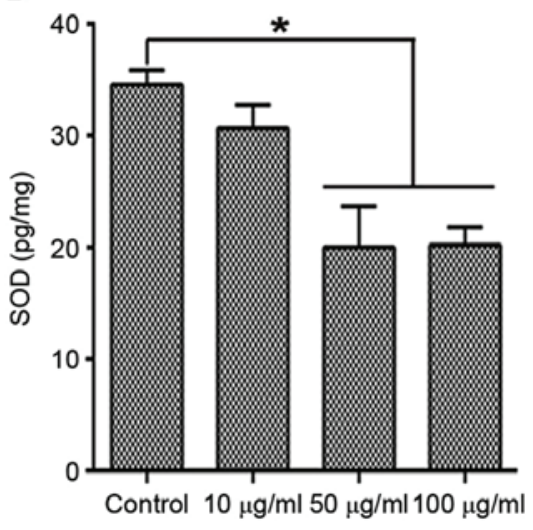

C

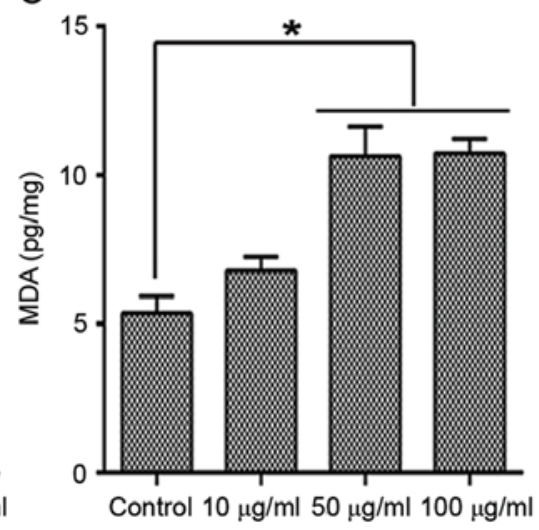

Figure 2. Cell proliferation and levels of SOD and MDA in HCECs pre-treated with Hst1 and irradiated with ultraviolet light. (A) HCEC proliferation was measured using an MTT assay. (B) ELISA analysis of SOD. (C) ELISA analysis of MDA. Values are expressed as the mean value of 3 independent experiments \pm the standard deviation. ${ }^{*} \mathrm{P}<0.05$; ${ }^{* *} \mathrm{P}<0.01$ vs. control. SOD, superoxide dismutase; MDA, malondialdehyde; HCEC, human corneal epithelial cell; Hst, histatin.

compared with that in non-treated control HCECs. By contrast, Bax expression was significantly downregulated in Hst1-treated cells after irradiation (Fig. 4C-E). These results suggested that Hst1 may be a potential prophylactic therapeutic agent to protect against UV damage. Further studies may demonstrate that Hst1 improves corneal epithelial wound healing in UV-damaged eyes.

\section{Discussion}

Irradiation of cells with UV light triggers a variety of signaling cascades that promote apoptosis. UV light is absorbed by the cornea, resulting in the generation of large amounts of free radicals, which may damage biological tissues if the supply of free radical scavengers in the irradiated tissue is insufficient (13). 
A

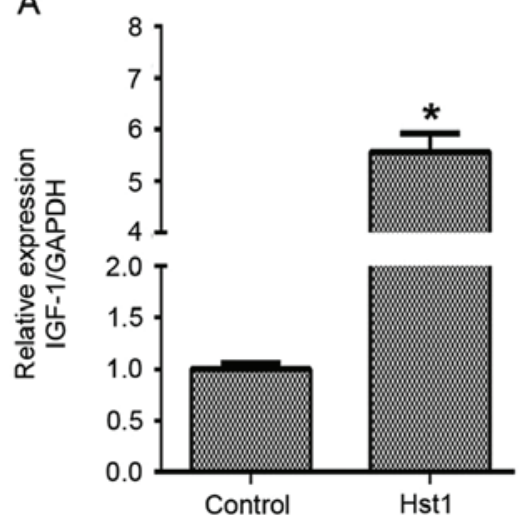

B

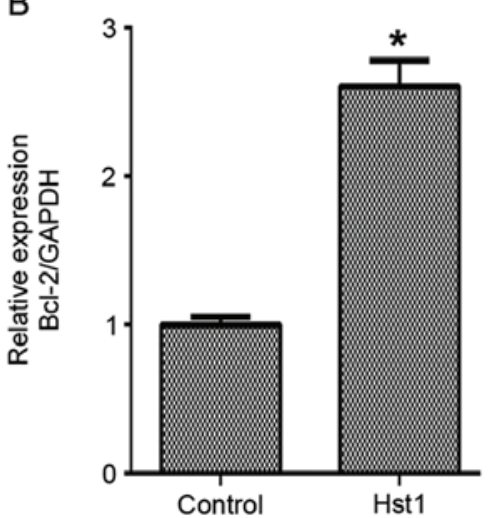

C

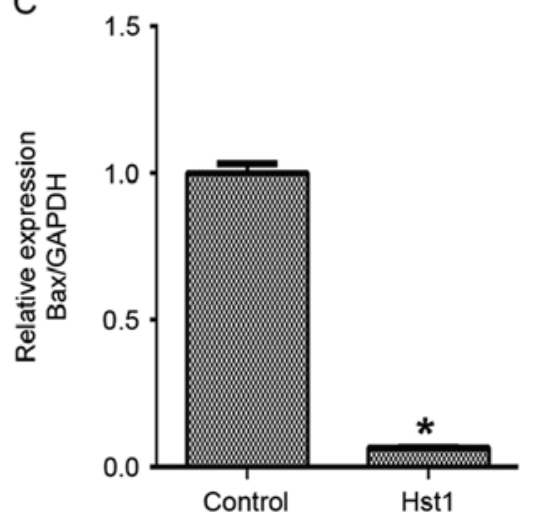

Figure 3. Protective effect of Hst1 against ultraviolet irradiation-induced damage to human corneal epithelial cells. Expression of (A) IGF-1, (B) Bcl-2 and $(\mathrm{C})$ Bax as detected by reverse transcription-quantitative polymerase chain reaction. " $\mathrm{P}<0.05$ vs. control. IGF, insulin-like growth factor; Bcl-2, B-cell lymphoma 2; Bax, Bcl-2-associated X protein; Hst, histatin.

A

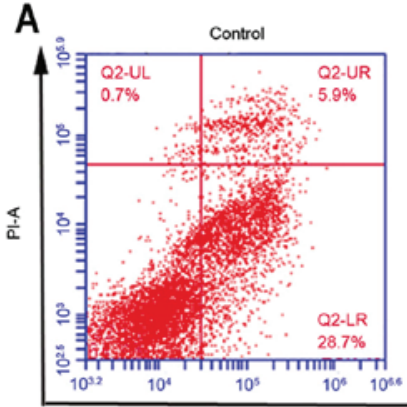

Annexin V FITC-A
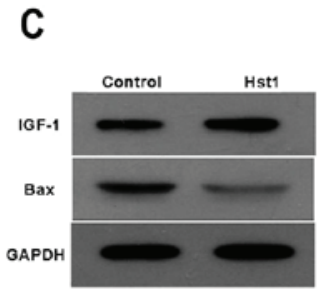

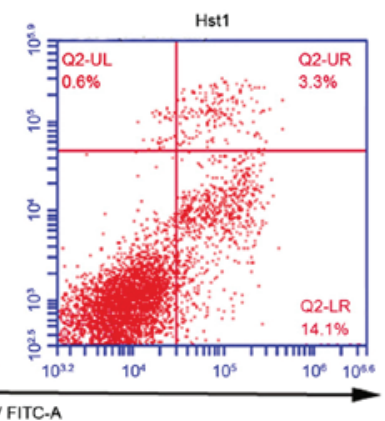

D

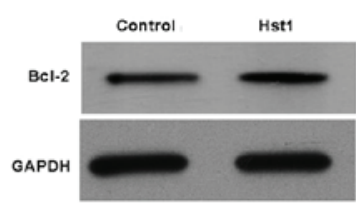

B
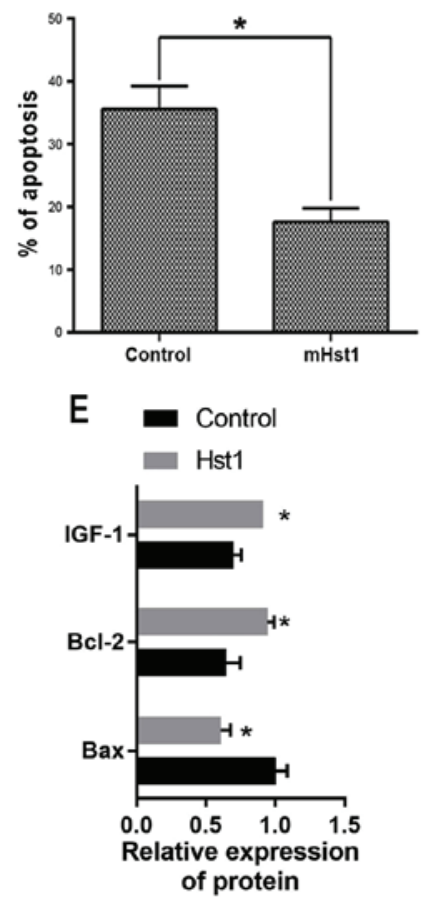

Figure 4. Protective effect of Hstl against ultraviolet irradiation-induced damage to HCECs. (A) Cell apoptosis assay. (B) The percentage of HCECs undergoing apoptosis. Expression of (C) IGF-1, Bax and (D) Bcl-2, as detected by western blotting and (E) western blot analysis. * P<0.05 vs. control. Hst, histatin; IGF, insulin-like growth factor; Bcl-2, B-cell lymphoma 2; Bax, Bcl-2-associated X protein; HCEC, human corneal epithelial cell; FITC, fluorescein isothiocyanate; PI, propidium iodide; UL, upper left; LR, lower right.

It is well known that $\mathrm{UV}$ radiation causes cell damage and even the death of cells located on the ocular surface $(13,14)$, and this damage to corneal epithelial cells contributes to ocular pathologies such as photokeratitis. The present study was performed to determine whether Hstl protects HCECs against UV radiation. The alamarBlue ${ }^{\circledR}$ assay was performed to evaluate differences between the viability of HCECs treated with Hst1 and control HCECs treated with PBS prior to irradiation with UV light for time periods of 1,2 and $3 \mathrm{~h}$, respectively. The results demonstrated that relevant doses $\left(0.072,0.144\right.$ and $\left.0.216 \mathrm{~J} / \mathrm{cm}^{2}\right)$ of UV radiation decreased the viability of HCECs. However, HCECs pre-treated with Hst1 were less susceptible to damage by UV radiation, suggesting a protective effect of Hst1.

Histatins are anti-microbial and anti-fungal proteins found in human saliva, and have been demonstrated to have a role in wound closure (10). Certain mammalian anti-microbial peptides were found to induce the expression of proteoglycans that promote cell proliferation, migration, angiogenesis and collagen synthesis, all of which are involved in the wound healing process (15). Due to their specific distribution in the human body, studies on Hsts have mostly concentrated 
on their role in the oral environment (16). The present study revealed that Hst1 protected HCECs and decreased their entry into apoptosis. Free radicals may inactivate $\mathrm{Na}^{+}, \mathrm{K}^{+}$and adenosine triphosphate-dependent enzymes in the corneal epithelium, resulting in disorders of cell metabolism. At the same time, they consume large amounts of anti-oxidants, which decreases the anti-oxidant capacity of biological tissue as indicated by increased MDA and decreased SOD levels, resulting in tissue damage (17). The results of the present study demonstrated that pre-treatment with Hst1 decreases SOD activity and increases MDA levels compared with those in untreated UV-irradiated HCECs, indicating that free radical oxidation reactions are involved in the corneal damage produced by UV light.

IGF-1 is the most important growth factor known to regulate cell proliferation, migration and apoptosis, and its expression is elevated in the vitreous of diabetic retinopathy patients. Bcl-2 and Bax mRNA have been detected in the primary cultures of three types of corneal cells, and are known to be involved in regulating apoptosis in corneal cells (18). In the present study, IGF-1 and Bcl-2 expression were increased in the Hst1 group, while Bax expression was decreased compared with that in untreated UV-irradiated HCECs.

Our group will continue to study the underlying mechanisms involved in UV-induced damage to biological tissue, with the goal of gaining novel information that may be used to help prevent or treat certain diseases caused by exposure to UV light. These results of the present suggested that Hst1 may be a potential prophylactic therapeutic agent to protect against UV damage. Further studies may demonstrate that Hstl also improves corneal epithelial wound healing in UV-damaged eyes. Studies on corneal damage produced by exposure to UV light may provide a factual or theoretical basis for the clinical use of Hst1, and a better understanding of its pharmacological effects.

\section{References}

1. Ng J, Coroneo MT, Wakefield D and Di Girolamo N: Ultraviolet radiation and the role of matrix metalloproteinases in the pathogenesis of ocular surface squamous neoplasia. Investigative Ophthalmol Visual Sci 49: 5295-5306, 2008.

2. Youn HY, McCanna DJ, Sivak JG and Jones LW: In vitro ultraviolet-induced damage in human corneal, lens, and retinal pigment epithelial cells. Mol Vis 17: 237-246, 2011.

3. Halliwell B: Antioxidant defence mechanisms: From the beginning to the end (of the beginning). Free Radic Res 31: 261-272, 1999.
4. Cadet J, Berger M, Douki T, Morin B, Raoul S, Ravanat JL and Spinelli S: Effects of UV and visible radiation on DNA-final base damage. Biol Chem 378: 1275-1286, 1997.

5. Jou MJ, Peng TI, Hsu LF, Jou SB, Reiter RJ, Yang CM, Chiao CC, Lin YF and Chen CC: Visualization of melatonin's multiple mitochondrial levels of protection against mitochondrial $\mathrm{Ca}(2+)$-mediated permeability transition and beyond in rat brain astrocytes. J Pineal Res 48: 20-38, 2010.

6. Clydesdale GJ, Dandie GW and Muller HK: Ultraviolet light induced injury: Immunological and inflammatory effects. Immunol Cell Biol 79: 547-568, 2001.

7. vanderSpek JC, Offner GD, Troxler RF and Oppenheim FG: Molecular cloning of human submandibular histatins. Arch Oral Biol 35: 137-143, 1990.

8. Sabatini LM and Azen EA: Histatins, a family of salivary histidine-rich proteins, are encoded by at least two loci (HIS1 and HIS2). Biochem Biophys Res Commun 160: 495-502, 1989.

9. vanderSpek JC, Wyandt HE, Skare JC, Milunsky A, Oppenheim FG and Troxler RF: Localization of the genes for histatins to human chromosome 4q13 and tissue distribution of the mRNAs. Am J Hum Genet 45: 381-387, 1989.

10. Oudhoff MJ, Bolscher JG, Nazmi K, Kalay H, van't Hof W, Amerongen AV and Veerman EC: Histatins are the major wound-closure stimulating factors in human saliva as identified in a cell culture assay. FASEB J 22: 3805-3812, 2008.

11. Chiarelli F, Santilli F and Mohn A: Role of growth factors in the development of diabetic complications. Horm Res 53: 53-67, 2000.

12. Livak KJ and Schmittgen TD: Analysis of relative gene expression data using real-time quantitative PCR and the 2(-Delta Delta C(T)) method. Methods 25: 402-408, 2001.

13. Pauloin T, Dutot M, Joly F, Warnet JM and Rat P: High molecular weight hyaluronan decreases UVB-induced apoptosis and inflammation in human epithelial corneal cells. Mol Vis 15: 577-583, 2009.

14. Lu L, Wang L and Shell B: UV-induced signaling pathways associated with corneal epithelial cell apoptosis. Invest Ophthalmol Vis Sci 44: 5102-5109, 2003.

15. Hirsch T, Spielmann M, Zuhaili B, Fossum M, Metzig M, Koehler T, Steinau HU, Yao F, Onderdonk AB, Steinstraesser L and Eriksson E: Human beta-defensin-3 promotes wound healing in infected diabetic wounds. J Gene Med 11: 220-228, 2009.

16. Kavanagh K and Dowd S: Histatins: Antimicrobial peptides with therapeutic potential. J Pharm Pharmacol 56: 285-289, 2004.

17. Rivera-Pastrana DM, Gardea AA, Yahia EM, Martinez-Téllez MA and González-Aguilar GA: Effect of UV-C irradiation and low temperature storage on bioactive compounds, antioxidant enzymes and radical scavenging activity of papaya fruit. J Food Sci Technol 51: 3821-3829, 2014

18. Li Q, Weng J, Mohan RR, Bennett GL, Schwall R, Wang ZF, Tabor K, Kim J, Hargrave S, Cuevas KH and Wilson SE: Hepatocyte growth factor and hepatocyte growth factor receptor in the lacrimal gland, tears, and cornea. Invest Ophthalmol Vis Sci 37: 727-739, 1996.

This work is licensed under a Creative Commons Attribution-NonCommercial-NoDerivatives 4.0 International (CC BY-NC-ND 4.0) License. 